Print ISSN: $2735-4121$

Online ISSN : $2735-413 \mathrm{X}$

\title{
The Effect of Passive Range of Motion Exercises on Hemodynamic Parameters of Mechanically Ventilated Patients
}

\author{
Ayat Mohammed Fahmy 1, Asmaa Ibrahim Abosaeda 2, Nahed Attia Kandeel 3 \\ 1Demonstrator of Critical Care and Emergency Nursing, Faculty of Nursing, Mansoura University, \\ Egypt.ayatfahmy1991@gmail.com \\ 2Assist. Professors of Critical Care and Emergency Nursing, Faculty of Nursing, Mansoura \\ University, Egypt.hyn_asmaa@yahoo.com \\ 3 Professors of Critical Care and Emergency Nursing, Faculty of Nursing, Mansoura University, \\ Egypt.Nahed_Kandeel2000@yahoo.com
}

\begin{abstract}
Background: Mechanically ventilated patients are often confined to bed rest for long periods which make them at high risk for impairment in different body systems. Evidence suggests that passive range of motion exercise for mechanically ventilated patients is a safe and effective intervention that can have a significant impact on patients' clinical outcomes. Aim: The aim of this study was to investigate the effect of passive range of motion exercises on hemodynamic parameters of mechanically ventilated patients. Method: The study has a quasi-experimental research design with a convenience sample of 112 adult mechanically ventilated patients from the anesthesia and neurosurgery intensive care units at Mansoura University Hospital in Egypt. Data were collected using patient's hemodynamic parameters assessment tool. Results: Statistically significant differences were noted between the intervention and control groups regarding the mean of physiological parameters including the respiratory rate, oxygen saturation, heart rate, systolic and diastolic blood pressure, and mean arterial pressure across the four measurement time points including baseline measurement, and 5, 20, and 60 minutes after exercises $(\mathrm{P}<0.05)$. On the contrary, no statistically significant changes were detected in the central venous pressure measures between the two groups $(\mathrm{P}=0.929)$. Conclusion and Recommendations: Passive range of motion exercises are considered as an effective method for stabilizing physiological parameters among mechanically ventilated patients. Hence, it can be incorporated as an adjunct intervention in the routine nursing care of mechanically ventilated patients. Further large-scale studies are required to contribute to the evidence-based care and support using this intervention.

Keywords: Hemodynamic Parameters, Mechanically Ventilated Patients, Passive Range of Motion Exercises.
\end{abstract}




\section{Introduction}

Mechanically ventilated patients (MVPs) are usually confined to strict bed rest with limited mobility due to the severity of their underlying illness and the medications they receive in intensive care units (ICUs) such as sedatives and neuromuscular blocking agents (Phelan, Lin, Mitchell, \& Chaboyer, 2018; Younis \& Ahmed, 2015). These patients frequently require life support interventions, ventilator assistance, and invasive monitoring (Halton, 2017). Immobility is documented as a significant risk for increased patients' morbidity and mortality rates (Higgins, Helm, Gould, \& Kindel, 2018). Moreover, bed rest and restraint still have a significant role in the development of neuromuscular disorders and functional ability impairment that delay recovery (Wang, 2020).

Prolonged bed rest and immobility are associated with a series of complications that affect the function of different body systems such as pneumonia, urinary tract infection, pressure ulcer (Naito, Kamiya, Morishima, \& Ishikawa, 2020), deep vein thrombosis (Cao et al., 2020), and ICU-acquired weakness (Zorowitz, 2016). Additionally, it may lead to the development of adverse effects such as rapid reductions in muscle mass and bone mineral density (Parry \& Puthucheary, 2015). It can also cause muscle weakness, difficult weaning from mechanical ventilation (MV), cognitive impairments, and delayed hospital discharge (Wang, 2020).

Passive exercise is described as the manipulation of the body or a limb within available limits without voluntary effort or muscle contraction (Trinity \& Richardson, 2019). The passive activities can be manually provided for critically ill patients by the nurses or therapists or by machines such as continuous passive motion machines or cycle ergometers (Brenner, 2018). If the passive exercise is delivered safely, it will be beneficial for MVPs who are unable to tolerate progressive activities. It will also facilitate ventilator weaning, shorten ICU length of stay (LOS), and improve the quality of life and general health status (Amidei, 2012).

Early passive mobilization for MVPs has a significant positive effect on different body systems and the hemodynamic parameters (Freitas et al., 2012). On the same line, a study conducted by Ningtyas, Pujiastuti, and Indriyawati (2017) revealed that progressive mobilization of critically ill patients can stabilize their hemodynamic status. Several recent studies showed that early mobilization (EM) is a safe, simple, feasible, and cost-effective technique (Elsayed, Dahroug, \& Halawa, 2020; Jacob et al., 2021; Semsar-kazerooni, Dima, Valiquette, Berube-Dufour, \& Goldfarb, 2020; Taito, Shime, Ota, \& Yasuda, 2016; Vieira et al., 2020).

Much novel literatures reported that early passive range of motion (PROM) exercises improve the cardiopulmonary functions (Elsayed et al., 2020), prevent delirium, and decrease the length of ICU and hospital stay (Dirkes \& Kozlowski, 2019). This subsequently will reduce the cost of health care services (Kumar, Romero, \& Dharaneeswaran, 2020). Moreover, it is considered as a non-invasive technique for coordinating the physiological responses, reducing the severity of pain (Amidei \& Sole, 2013), and alleviating anxiety levels (Klein, Bena, Mulkey, \& Albert, 2018). 
Despite the benefits of EM for MVPs, there are some potential barriers for its implementation such as patient's sedation practices, hemodynamic instability, inadequate rehabilitation equipment in ICUs, shortage of staff (Tadyanemhandu, van Aswegen, \& Ntsiea, 2018), inadequate time, and lack of nurses' education regarding the benefits of EM. These factors contribute to the limited mobilization of MVPs (C. Kim, Kim, Yang, \& Choi, 2019). Furthermore, the most problem facing nursing practice is the gap between education and training on EM. Overcoming this barrier requires continuous in service-training for nurses (Gilson, 2019).

Hemodynamic parameters are important criteria for accurate diagnosis and management of critically ill patients. It provides essential data about the circulatory function and efficiency of treatment. It also delivers reflecting data about the cardiopulmonary system alterations (Morton \& Fontaine, 2018). The main vital physiological parameters involve the heart rate (HR), blood pressure (BP), respiratory rate (RR), oxygen saturation $\left(\mathrm{SPO}_{2}\right)$, and central venous pressure (CVP) monitoring (Comisso, Lucchini, Bambi, Giusti, \& Manici, 2018).

Delayed mobility of MVPs is a major challenge for critical care nurses. In the selected study settings, patients' sedation and hemodynamic instability can delay EM. Lack of knowledge and awareness about the valuable benefits of an early PROM for MVPs is another challenge. According to the Centers for Disease Control (CDC, 2018), approximately 300,000 people are placed on MV each year in the United States, and many complications can arise related to ventilation with prolonged immobility.
Ventilator-associated events (VAE) including pulmonary embolism, pulmonary edema, ventilator-associated pneumonia, sepsis, and even barotrauma can lead to increased length of hospital stay and sometimes even death (CDC, 2018).

To the best of our knowledge, studies that investigated the effect of PROM exercises on physiological parameters among MVPs in Egypt are scarce. Only one Egyptian study conducted in ICUs affiliated to Tanta University Hospital addressed this issue (Younis \& Ahmed, 2015). The same study reported the effectiveness of PROM exercises in improving patients' hemodynamic parameters and reducing their pain. However, this study has a small sample size which limits the generalizability of the findings. Hopefully, the current investigation might generate attention and motivation for further research studies in this area.

\section{Aim of the Study}

The aim of this study was to investigate the effect of PROM exercises on hemodynamic parameters of mechanically ventilated patients.

\section{Research Hypothesis}

Mechanically ventilated patients who receive PROM exercises will have better hemodynamic parameters than those who do not receive this intervention.

\section{Method Research Design}

A quasi-experimental research design was utilized to conduct this study. This design aims to examine whether there is a causal relationship between independent and dependent variables (Loewen \& Plonsky, 2015). Quasiexperimental designs are more frequently used in nursing as it is more suitable for the real world natural setting than true 


\section{experimental research designs (LoBiondo-Wood, \& Haber, 2018). Setting}

This research was conducted in the Anesthesia and Neurosurgery ICUs affiliated to Mansoura University Hospital in Egypt. The Anesthesia ICU includes 8 beds and provides care for patients who experience major postoperative complications such as postpartum hemorrhage, postpartum preeclampsia, over-sedation, and respiratory failure. The Neurosurgery ICU involves 5 beds and it provides services to patients who have postoperative neurological disorders. The two units are well equipped with advanced equipment and manpower needed for patients' management. The nurse-patient ratio in the selected ICUs is nearly $1: 2$.

\section{Subjects}

A convenience sample of 112 adult MVPs was enrolled in this study according to the following criteria; patients older than 18 years old of both sexes, undergoing $\mathrm{MV}$, and have stable hemodynamic status. We excluded patients who had orthopedic or vascular problems, actual or suspected deep venous thrombosis, pelvic or spinal injuries, and cardiac dysrhythmias. Patients who were hemodynamically unstable were also excluded from this investigation. Participants were randomly assigned into two groups: the intervention group who received the PROM exercises and the control group who received the routine care of the unit.

\section{Sample Size Calculation}

The sample size was estimated through DSS research.com sample size calculator software, at $3 \% \infty$ error (97.0\% significance) and $10.0 \% \beta$ error $(90.0 \%$ power of the study). The calculated sample size was 51 in each group. A 10\% was added for better data and follow-up drop. Therefore, the total sample size was 112 patients (56 in the intervention group and 56 in the control group).

\section{Data Collection Instrument}

Data were collected using the Patients' Hemodynamic Parameters Assessment Tool. It was developed by the primary investigator (PI) after reviewing the recent relevant literature (Amidei \& Sole, 2013; Genc, Koca, \& Gunerli, 2014; Rezaeiki, Najafi Dolatabad, Afrasiabifar, \& Zoladl, 2019; Younis \& Ahmed, 2015). This tool involved two main parts as follows:

\section{Part I: Patients' Demographic Characteristics and Health Relevant Data}

This part encompassed the participants' age, gender, marital status, educational level, and occupation. It also involved participants' health-relevant data such as the admission date, medical diagnosis, past medical history, and ventilator parameters.

Part II: Hemodynamic Parameters Assessment Sheet

This part assessed patients' hemodynamic parameters including the $\mathrm{RR}, \mathrm{SPO}_{2}, \mathrm{HR}$, systolic blood pressure (SBP), diastolic blood pressure (DBP), mean arterial pressure (MAP), and CVP. These parameters were monitored four times using an electronic monitor (preintervention, and 5,20, and 60 minutes post-intervention).

\section{Validity and Reliability}

The content validity of the tool was tested by a jury of five experts in Critical Care Nursing, and Medicine. Their comments and opinions were considered. The reliability of the tool was assessed by using the Cronbach's alpha test that was 0.89 which indicates a reliable tool. 
The Effect of Passive Range of Motion Exercises on etc...

\section{Pilot Study}

A pilot study was conducted on 11 patients ( $10 \%$ of the total sample) to ensure the feasibility, relevancy, and applicability of the data collection tool. Participants in the pilot study were excluded from the main study.

\section{Ethical Considerations}

Ethical approval was secured from the Research Ethics Committee of the Faculty of Nursing - Mansoura University. Informed consent was obtained from the patient's next of kin after giving them details about the study including the aim, procedure, benefits, and risks. They were informed that participation in the study was voluntary. They were also notified that they had the right to seek to withdraw the patient from the study at any time without responsibility. Furthermore, they were assured about the confidentiality of the patient's personal information.

\section{Data Collection Process}

Data were collected by the PI between May and October 2019 throughout three phases including the preparation, implementation, and evaluation.

\section{Preparation Phase}

An official letter to conduct this investigation was granted from the responsible authority of the hospital after explaining the nature of the study. Before beginning the study, the PI had received practical preparation on how to perform PROM exercises by a physiotherapist from the 'Smart Center for Physiotherapy' in Mansoura in January 2019. All patients admitted to the selected ICUs were screened to enroll the eligible patients. The PI interviewed patients' families and explained to them the details of the study. Once the next of kin agreed to allow the patient to participate in the study, the data collection process was commenced. The baseline data were collected from the patients' records, including demographic characteristics and health-relevant data at admission.

\section{Implementation Phase}

Eligible patients were randomly assigned into two equal groups; the intervention group and the control group. Each group involved 56 patients. The intervention group received PROM exercises program. The original program was adopted from Genc et al., (2014) and the time frame of the program (baseline measurement, and 5, 20, and 60 minutes) was adopted from Younis \& Ahmed (2015).

The program consisted of 20 minutes of flexion-extension movements for both limbs (one session/day). The patient was placed in a supine position and received 10 repetitive upper and lower extremity PROM exercises. For the upper extremities, PROM exercises included fingers flexion and extension, wrist flexion, extension, ulnar and radial deviation; elbow flexion, extension, forearm supination and pronation; and shoulder flexion, extension, abduction, adduction, internal and external rotation. For lower extremity, PROM exercises included toe flexion and extension, ankle dorsiflexion, inversion and eversion, knee flexion, and extension and hip flexion, extension, abduction, adduction, and internal and external rotation.

The control group was given the routine care of the unit without PROM exercises.

\section{Evaluation Phase}

During this phase, the PI obtained the physiological parameters through four phases using the electronic monitors as follow:

- Phase 1 (time 0): involved baseline measurement of the physiological 
parameters including the $H R, R R$, SBP and DBP, MAP, $\mathrm{SpO}_{2}$, and CVP.

- Phase 2 (time 1): the physiological parameters were measured 5 minutes following PROM exercises.

- Phase 3 (time 2): the physiological parameters were measured 20 minutes after PROM exercises.

- Phase 4 (time 3): the physiological parameters were measured 60 minutes after PROM exercises.

After completion of the exercise program, the patient was rested for about 60 minutes without any activities until the researcher obtained the last reading. Patients' physiological parameters were monitored using the electronic monitors at the end of the rest period.

\section{Data Analysis}

The Statistical Package for Social Sciences (SPSS) Program version 22 was used for analyzing data. Qualitative data were described as numbers and percentages. However, quantitative data were expressed as mean \pm standard deviation (SD) or median if normally distributed and interquartile range (IQR) if not normally distributed. The ChiSquare test $\left(\chi^{2}\right)$ was used to compare between the two groups. The repeated measures ANOVA test was used to examine the differences between the two groups regarding the hemodynamic parameters across the four measurement time points. The statistical significance level $P$ value was set at less than 0.05 .

Results

Table 1 showed that slightly more than half of the studied groups were males and more than one-third of them were in the age group between 51-60 years old. The mean age of the participants was $47 \pm 11$ and $48.6 \pm 12.2$ years, respectively. Additionally, most of the patients in the intervention group and the control group were married (76.8\% \& $82.1 \%$ respectively). Additionally, $42.9 \%$ of the intervention group had achieved a high school educational level and $41.1 \%$ of the control group had achieved a primary level of education. Half of the intervention group (50\%) and $44.6 \%$ of the control group were employed. The most common medical diagnoses among the studied groups were neurosurgical disorders followed by post-operative disorders. In addition, the majority of patients in the studied groups were intubated via an endotracheal tube, and slightly more than half of them were on SIMV mode. No statistically significant differences were detected between the two groups regarding their demographic characteristics and health relevant data. 
The Effect of Passive Range of Motion Exercises on etc...

Table 1 Participants' Demographic Characteristics and Health Relevant Data

\begin{tabular}{|c|c|c|c|c|c|c|c|}
\hline \multirow{2}{*}{ Variable } & \multirow{2}{*}{ Category } & \multicolumn{2}{|c|}{ Passive exercise Group } & \multicolumn{2}{|c|}{ Control Group } & \multicolumn{2}{|c|}{ Chi square test } \\
\hline & & $\mathbf{N}$ & $\%$ & $\mathbf{n}$ & $\%$ & $\chi^{2}$ & P value \\
\hline \multirow{2}{*}{ Gender } & Male & 29 & 51.8 & 31 & 55.4 & \multirow{2}{*}{0.144} & \multirow{2}{*}{0.71} \\
\hline & Female & 27 & 48.2 & 25 & 44.6 & & \\
\hline \multirow{5}{*}{ Age (years) } & $18-30$ & 3 & 5.4 & 5 & 8.9 & \multirow{5}{*}{2.454} & \multirow{5}{*}{0.683} \\
\hline & $31-40$ & 15 & 26.8 & 10 & 17.9 & & \\
\hline & $41-50$ & 13 & 23.2 & 11 & 19.6 & & \\
\hline & $51-60$ & 20 & 35.7 & 22 & 39.3 & & \\
\hline & $>60$ & 5 & 8.9 & 8 & 14.3 & & \\
\hline Mean \pm SD & \multicolumn{5}{|c|}{$48.6 \pm 12.2$} & & \\
\hline \multirow{4}{*}{$\begin{array}{l}\text { Marital } \\
\text { status }\end{array}$} & Single & 5 & 8.9 & 3 & 5.4 & \multirow{4}{*}{$1 . \wedge \wedge \vee$} & \multirow{4}{*}{0.637} \\
\hline & Married & 43 & 76.8 & 46 & 82.1 & & \\
\hline & Widow & 8 & 14.3 & 6 & 10.7 & & \\
\hline & Divorced & 0 & 0 & 1 & 1.8 & & \\
\hline \multirow{4}{*}{$\begin{array}{c}\text { Education } \\
\text { level }\end{array}$} & Illiterate & 7 & 12.5 & 5 & 8.9 & \multirow{4}{*}{2.267} & \multirow{4}{*}{0.519} \\
\hline & Primary & 20 & 35.7 & 23 & 41.1 & & \\
\hline & High-school & 24 & 42.9 & 19 & 33.9 & & \\
\hline & University & 5 & 8.9 & 9 & 16.1 & & \\
\hline \multirow{3}{*}{ Occupation } & Employee & 28 & 50 & 25 & 44.6 & \multirow{3}{*}{0.862} & \multirow{3}{*}{0.650} \\
\hline & Unemployed & 23 & 41.1 & 23 & 41.1 & & \\
\hline & Retired & 5 & 8.9 & 8 & 14.3 & & \\
\hline \multirow{4}{*}{$\begin{array}{l}\text { Medical } \\
\text { diagnosis }\end{array}$} & $\begin{array}{c}\text { Neurosurgical } \\
\text { disorders }\end{array}$ & 25 & 44.6 & 26 & 46.4 & \multirow{4}{*}{0.436} & \multirow{4}{*}{1.000} \\
\hline & $\begin{array}{c}\text { Respiratory } \\
\text { disorders }\end{array}$ & 9 & 16.1 & 8 & 14.3 & & \\
\hline & $\begin{array}{c}\text { Autoimmune } \\
\text { disorders }\end{array}$ & 1 & 1.8 & 2 & 3.6 & & \\
\hline & $\begin{array}{l}\text { Post-operative } \\
\text { disorders }\end{array}$ & 21 & 37.5 & 20 & 35.7 & & \\
\hline \multirow{2}{*}{$\begin{array}{c}\text { Type of } \\
\text { intubation }\end{array}$} & Endotracheal tube & 55 & 98.2 & 53 & 94.6 & \multirow[b]{2}{*}{ FET } & 0.618 \\
\hline & $\begin{array}{c}\text { Tracheostomy } \\
\text { tube }\end{array}$ & 1 & 1.8 & 3 & 5.4 & & \\
\hline \multirow{5}{*}{$\begin{array}{c}\text { Ventilation } \\
\text { mode }\end{array}$} & SIMV & 30 & 53.5 & 32 & 57.1 & \multirow{5}{*}{0.865} & \multirow{5}{*}{0.915} \\
\hline & $\mathrm{A} / \mathrm{C}$ & 9 & 16.1 & 11 & 19.6 & & \\
\hline & PSV & 11 & 19.6 & 9 & 16.1 & & \\
\hline & CPAP & 3 & 5.4 & 2 & 3.6 & & \\
\hline & Others & 3 & 5.4 & 2 & 3.6 & & \\
\hline
\end{tabular}

Tables 2 compares the physiological parameters between the study groups

2: Chi-square or Fisher's exact test, *

Statistically significant $\mathrm{P} \leq 0.05, \mathrm{~N}$ :

Number of participants. SIMV:

Synchronized Intermittent Mandatory

Ventilation, A/C: Assis /Control, PSV:

Pressure Support Ventilation, CPAP:

Continuous Positive Airway Pressure

\section{RR \& HR}

The results showed a remarkable increase in the mean scores of the RR and HR which were noted five minutes $(18.25 \pm 1.97,96.95 \pm 6.8$ respectively $)$ and 20 minutes after PROM exercises $(18.98 \pm 1.91,99.29 \pm 6.46$ respectively) as compared to the mean scores before the intervention $(15.7 \pm 2.1,89.93 \pm 6.8$ respectively). However, 60 minutes following the PROM exercises (Time 3), the mean scores were near to the preintervention mean scores. On the contrary, no statistically significant changes were noted in the same parameters in the control group $(P>0.0005)$. 
$\mathrm{SPO}_{2}$

The findings illustrated a statistically significant decrease in the $\mathrm{SPO}_{2}$ in the intervention group after 5 and 20 minutes of the PROM exercises $(97.5 \pm 0.97,97.4 \pm 0.95$ respectively) as compared to the mean scores before the intervention (98.7 \pm 0.98$)$. However, after 60 minutes (Time 3) the mean scores $(98.3 \pm 0.73)$ were nearly equal to the pre-intervention mean scores. Conversely, no statistically significant difference was found in participants'
$\mathrm{SPO}_{2}$ within the control group during the four phases of the study $(P>0.05)$.

\section{SBP, DBP and MAP}

Astatistically significant reduction in the DBP, DBP, and MAP $(P<0.0005)$ was noted in the intervention group compared with the control group throughout the four measurement time points.

CVP

Nostatistically significant changes were noted in the participant's CVP measures $(\mathrm{F}=0.050, \quad P=0.929$, Partial $\eta 2=0.000$ ) between the two groups.

Table 2Comparing Hemodynamic Parameters between the Study Groups across the Four Measurement Time Points

\begin{tabular}{|c|c|c|c|c|c|c|}
\hline \multirow{2}{*}{ Variable } & \multirow{2}{*}{ Group } & Baseline & After 5-min & After 20-min & After 60-min & \multirow{2}{*}{$\begin{array}{c}\text { RM-ANOVA Between } \\
\text { Groups }\end{array}$} \\
\hline & & $\overline{\mathbf{x}} \pm$ SD & $\overline{\mathbf{x}} \pm$ SD & $\overline{\mathbf{x}} \pm$ SD & $\overline{\mathbf{x}} \pm \mathbf{S D}$ & \\
\hline \multirow{2}{*}{$\mathbf{R R}$} & Intervention Group & $15.7 \pm 2.1$ & $18.25 \pm 1.97$ & $18.98 \pm 1.91$ & $16.05 \pm 1.9$ & \multirow{2}{*}{$\begin{array}{c}\mathrm{F}=240.263 \\
\mathrm{P}<0.0005 \\
\text { Partial } \eta^{2}=0.686\end{array}$} \\
\hline & Control Group & $13.98 \pm 3$ & $13.95 \pm 3$ & $14.14 \pm 2.7$ & $14.41 \pm 2.8$ & \\
\hline \multirow[b]{2}{*}{ HR } & Intervention Group & $89.93 \pm 6.8$ & $96.95 \pm 6.8$ & $99.29 \pm 6.46$ & $93.14 \pm 5.9$ & \multirow{2}{*}{$\begin{array}{c}\mathrm{F}=57.318 \\
\mathrm{P}<0.0005 \\
\text { Partial }^{2}=0.343\end{array}$} \\
\hline & Control Group & $91.6 \pm 10.9$ & $93.3 \pm 11.8$ & $92.8 \pm 11.6$ & $93.7 \pm 11.1$ & \\
\hline \multirow{2}{*}{$\mathrm{SPO}_{2}$} & Intervention Group & $98.7 \pm 0.98$ & $97.5 \pm 0.97$ & $97.4 \pm 0.95$ & $98.3 \pm 0.73$ & \multirow{2}{*}{$\begin{array}{c}\mathrm{F}=58.010 \\
\mathrm{P}<0.0005 \\
\text { Partial } \eta^{2}=0.345\end{array}$} \\
\hline & Control Group & $99.1 \pm 0.85$ & $99.0 \pm 0.99$ & $98.95 \pm 0.96$ & $99.18 \pm 0.76$ & \\
\hline \multirow{2}{*}{ SBP } & Intervention Group & $145.1 \pm 10.6$ & $136 \pm 9.9$ & $128.9 \pm 9.3$ & $124.2 \pm 9.1$ & \multirow{2}{*}{$\begin{array}{c}\mathrm{F}=95.862 \\
\mathrm{P}<0.0005 \\
\text { Partial } \eta^{2}=0.466\end{array}$} \\
\hline & Control group & $137.3 \pm 13.2$ & $137 \pm 13.2$ & $136.6 \pm 12.8$ & $135.2 \pm 11.6$ & \\
\hline \multirow[t]{2}{*}{ DBP } & Intervention Group & $88.4 \pm 8.6$ & $81.3 \pm 8.6$ & $78.6 \pm 7.7$ & $75.4 \pm 7.8$ & \multirow{2}{*}{$\begin{array}{c}\mathrm{F}=28.760 \\
\mathrm{P}<0.0005 \\
\text { Partial }^{2}=0.207\end{array}$} \\
\hline & Control Group & $83.5 \pm 11.8$ & $84.4 \pm 8.3$ & $84.2 \pm 7.2$ & $84.1 \pm 6.7$ & \\
\hline \multirow{2}{*}{ MAP } & Intervention Group & $101.8 \pm 7.1$ & $95.6 \pm 7.8$ & $90.3 \pm 7.8$ & $88.4 \pm 7.0$ & \multirow{2}{*}{$\begin{array}{c}\mathrm{F}=40.381 \\
\mathrm{P}<0.0005 \\
\text { Partial } \eta^{2}=0.269\end{array}$} \\
\hline & Control Group & $95.75 \pm 15$ & $97.95 \pm 9.4$ & $96.84 \pm 9.3$ & $96.55 \pm 9.1$ & \\
\hline \multirow{2}{*}{ CVP } & Intervention Group & $9.68 \pm 1.53$ & $9.66 \pm 1.49$ & $9.66 \pm 1.49$ & $9.77 \pm 1.45$ & \multirow{2}{*}{$\begin{array}{c}\mathrm{F}=0.050 \\
\mathrm{P}=0.929 \\
\text { Partial }^{2}=0.000\end{array}$} \\
\hline & Control Group & $10.55 \pm 2.45$ & $10.54 \pm 2.46$ & $10.54 \pm 2.47$ & $10.66 \pm 2.45$ & \\
\hline
\end{tabular}

$\overline{\mathrm{x}}$ : Mean, SD: Standard Deviation, * Statistically significant $P \leq 0.05$

\section{Discussion}

Early mobility of MVPs is a safe and feasible promising intervention used to improve functional mobility, increase ventilator-free days as well as reduce hospital LOS. It includes activities that progress from passive to active intervention (Hruska, 2016). There is growing evidence supporting the safety and benefits of EM that can have a significant positive impact on patients' outcomes such as facilitating functional rehabilitation and promoting muscle strength (da Silva Azevedo, \& Gomes, 
The Effect of Passive Range of Motion Exercises on etc...

2015). Thus, the current study focused on investigating the effect of PROM exercises on the hemodynamic parameters of MVPs.

The current study depicts no statistically significant differences between the intervention and control groups regarding their sociodemographic characteristics and healthrelevant data indicating the similarity of the study groups before the intervention. These findings were confirmed by Ahmed (2019) who reported that no statistically significant changes between the early ambulation and hospital care groups concerning their health profile data. Some studies reported similar findings (Azarfarin, Totonchi, Arizavi, \& Yousefi-Moghadam, 2015; Santos et al., 2019; Wang et al., 2021).

The findings of the present study revealed a significant increase in the mean scores of the RR and HR among the intervention group after 5, and 20 minutes of the PROM exercises as compared to the pre-intervention mean scores. However, after 60 minutes of the intervention, the mean scores of the RR and HR were near to the baseline mean scores. It is a well-known fact that increasing the HR after exercises may be attributed to the increased cardiac output and oxygen consumption (Burton, Stokes, \& Hall, 2004). Also, increased RR may be related to an increase the metabolic rate induced by passive exercises (Trinity \& Richardson, 2019).

Supporting our findings, Ahmed (2019) found a significant increase in the HR and peripheral pulse (PP) overtime during the ambulation attempts. This result may be due to increased oxygen demand associated with mobilization and stimulation of the sympathetic nervous system that can raise the hemodynamic readings (Genc et al., 2014). Similar to our results e Silva et al. (2019) reported a significant elevation in the HR mean score, already observed in the midpoint of the session and persists increased after the end of the intervention. In the same study, the HR has returned to baseline 5 minutes after stretching and stayed in this range at 20 minutes after stretching in both groups. This is because the heart and lungs may need extra oxygen during passive exercises to meet the demand by increasing the RR and HR (Santos et al., 2019).

An investigation was conducted by Asgari et al. (2015) to assess the effect of EM program on the HR and BP of patients with myocardial infarction showed a significant difference in the HR between the intervention and the control groups during the first and third days of mobilization. Another study conducted by Hickmann et al. (2020) found that the RR was increased during each active exercise and returning to baseline values after the end of the exercise. The researchers exhibited that changing the patient's position and physical activity both improve respiratory physiology. These results are inconsistent with the findings of another study which reported a significant decrease in HR and RR (Yilmaz Yelvar, Cirak, Parlak Demir, Dalkilinc, \& Bozkurt, 2016). This inconsistency may be due to the nature of the study population as their study involved chronic obstructive pulmonary disease (COPD) patients.

Oxygen saturation measurement is a vital and essential indicator for the effectiveness of MV. In the current study, decreased value of $\mathrm{SPO}_{2}$ was observed five and 20 minutes following the intervention compared with the preintervention mean scores. However, after 
60 minutes the mean scores were nearly equal to the pre-intervention mean scores. This finding is consistent with Younis \& Ahmed's (2015) study. Additionally, Hickmann et al. (2020) reported improvement in the $\mathrm{SPO}_{2}$ value in the subjects performing physical activities.

This finding is contradictory to a study that investigated the effects of an early bedside cycle exercise on intracranial and systemic hemodynamics in critically ill patients and reported no significant changes in the $\mathrm{SPO}_{2}$ value during the experimental procedure (Thelandersson, Nellgård, Ricksten, \& Cider, 2016). This disagreement may be due to the small sample size (20 patients) and that the majority of the participants were comatose and/or sedated. Additionally, an observational study examined the hemodynamic challenges to EM in patients after cardiac surgery reported no significant changes in the $\mathrm{SPO}_{2}$ value between two-staged mobilization procedures (Cassina, Putzu, Santambrogio, Villa, \& Licker, 2016). This contradiction could be due to the nature of the study population as all of them were not on MV.

The present study found a significant decrease in the patients' SBP, DBP, and MAP readings towards the normal values over time in the intervention group. Our findings are matched with Indriani, Santoso, Arwani, \& Mardiyono (2018) who noted a significant decrease in patients' SBP, DBP, and MAP toward stability after the progressive mobilization. Similarly, another study that examined the effect of passive movement on cardiovascular indices among stroke patients showed a significant decrease in the DBP and MAP (Achugbue, 2009). The same study concluded that the passive movement can cause a rise in blood flow to the immobilized tissues of stroke patients. On the contrary, a similar study revealed no significant differences in the hemodynamic parameters (SBP, DBP, and MAP) between the experimental and the control groups (Rezaeikia et al., 2019). This inconsistency may be because the passive movement in their study was only performed on the lower extremity, but in our study, passive exercises were performed on all body parts. Moreover, Hartoyo, Shobirun, Budiyati, and Rachmilia (2017) stated that there was an increase in participants' SBP and DBP after the progressive level I mobilization. This discrepancy may be due to the small sample size (15 participants).

Regarding the CVP values, the current study found no significant changes over time in the CVP readings $(P=0.929)$ between the intervention and control groups. These results are supported by previous research findings (Younis \& Ahmed, 2015). However, other studies reported a significant elevation in the CVP readings between the rest and the recovery period after passive exercise sessions for MVPs (Genc et al., 2014; Pires-Neto et al., 2013). This disagreement may be due to the study population as Genc's study involved MVPs receiving a low dose of vasopressor/inotropic support.

\section{Limitations}

This study involved a small size convenience sample and was conducted only in two ICUs in one university hospital. These factors limited the generalizability of the research findings.

\section{Conclusion and Recommendations}

Overall, the current study results are supported by other related studies that reported the positive effect of 
The Effect of Passive Range of Motion Exercises on etc...

PROM exercises on MVPs' hemodynamic parameters. The PROM exercise for MVPs is a safe and feasible nursing intervention. Thereby, the current findings supported our research hypothesis that PROM exercises attribute a significant positive effect on hemodynamic parameters of MVPs. Hence, critical care nurses should use this technique in the daily routine care of MVPs. Future research studies on different patient populations are required for generating more strong evidence to support this approach.

\section{Acknowledgments}

We would like to acknowledge the critical care nurses in the study setting for their assistance and support to accomplish this research.

\section{Declaration of Conflicting Interests}

The authors declared no potential conflicts of interest regarding the research or publication of the article.

\section{References}

Achugbue, F. S. (2009). The effects of therapeutic passive movement on cardiovascular response in stroke patients. Research Journal of Medical Sciences, 3(1), 12-5. Retrieved from: http://www.medwelljournals.com/f ullte...

Ahmed, H. H. (2019). The Effect of early ambulation on hemodynamic and perfusion indices post cardiac surgery. American Journal of Nursing, 7(4), 490-498.

DOI: 10.12691/ajnr-7-4-11

Amidei, C., \& Sole, M. L. (2013). Physiological responses to passive exercise in adults receiving mechanical ventilation. American Journal of Critical Care,22(4), 337-348. Retrieved from: https://doi.org/10.4037/ajcc201328 $\underline{4}$
Amidei, C. M. (2012). An exploratory study of physiologic responses to a passive exercise intervention in mechanically-ventilated critically ill adults. (Doctorate dissertation, University of Central Florida).

Asgari, M. R., Jafarpoor, H., Soleimani, M., Ghorbani, R., Askandarian, R., \& Jafaripour, I. (2015). Effects of early mobilization program on the heart rate and blood pressure of patients with myocardial infarction hospitalized at the coronary care unit. Middle East Journal of Rehabilitation and Health, 2(1). Retrieved from: http://eprints.semums.ac.ir/id/eprin $\mathrm{t} / 347$

Azarfarin, R., Totonchi, Z., Arizavi, Z., \& Yousefi-Moghadam, M. (2015). The effect of early mobility on respiratory indices of patients after open heart surgery. Iranian Journal of Cardiovascular Nursing, 4(3), 5462

Brenner, I. (2018). Effects of passive exercise training in hemiplegic stroke patients: A MiniReview. Sports Medicine and Rehabilitation Journal. 2018 (3), 1036.

Burton, D. A., Stokes, K., \& Hall, G. M. (2004). Physiological effects of exercise. Continuing Education in Anaesthesia Critical Care \& Pain, 4(6), 185-188. DOI:10.1093/bjaceaccp/mkh050

Cao, J., Li, S., Ma, Y., Li, Z., Liu, G., Liu, Y., ... Wu, X. (2020). Risk factors associated with deep venous thrombosis in patients with different bed-rest durations: a multi-institutional case-control study. International Journal of 


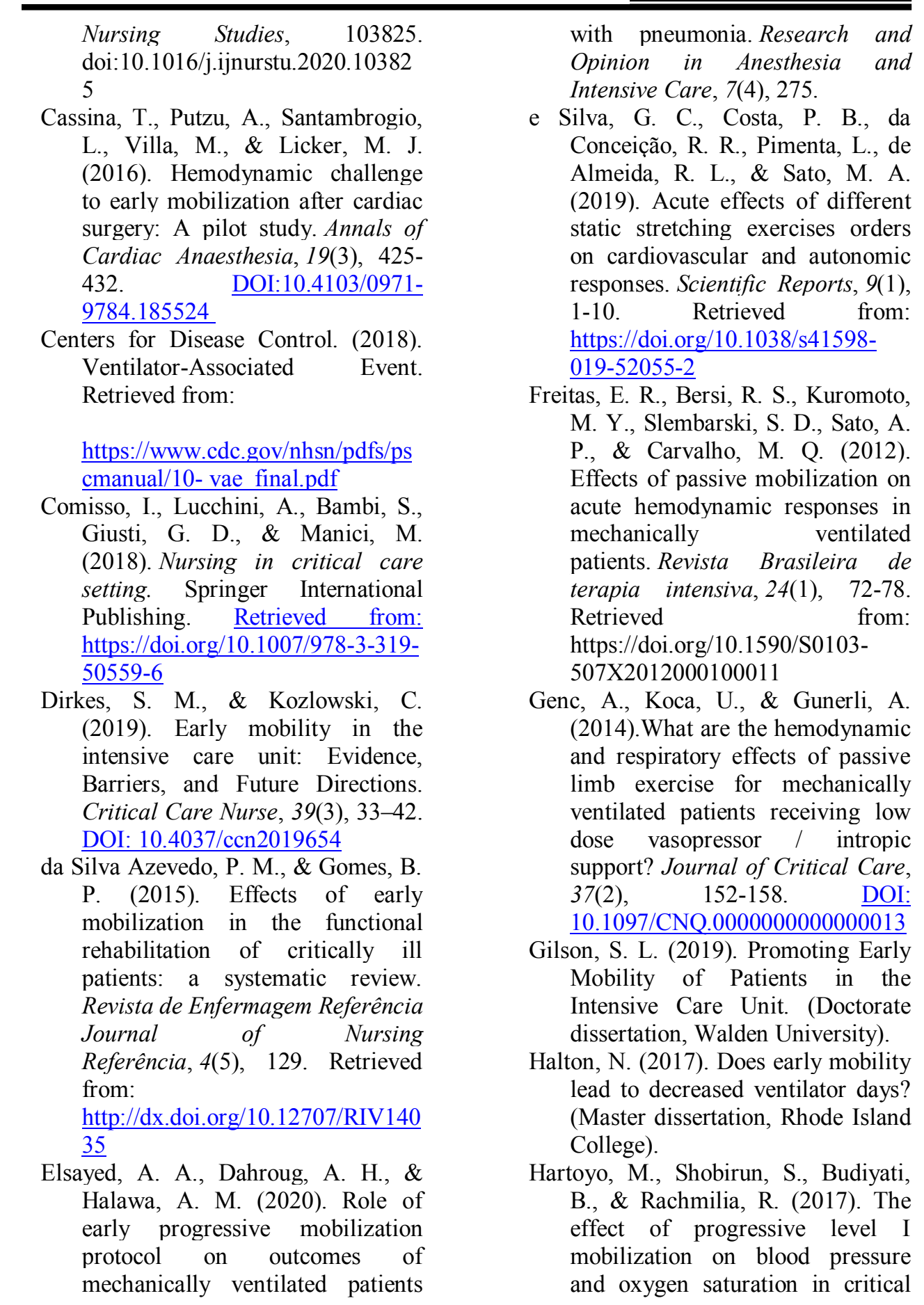


The Effect of Passive Range of Motion Exercises on etc...

\begin{tabular}{|c|c|}
\hline 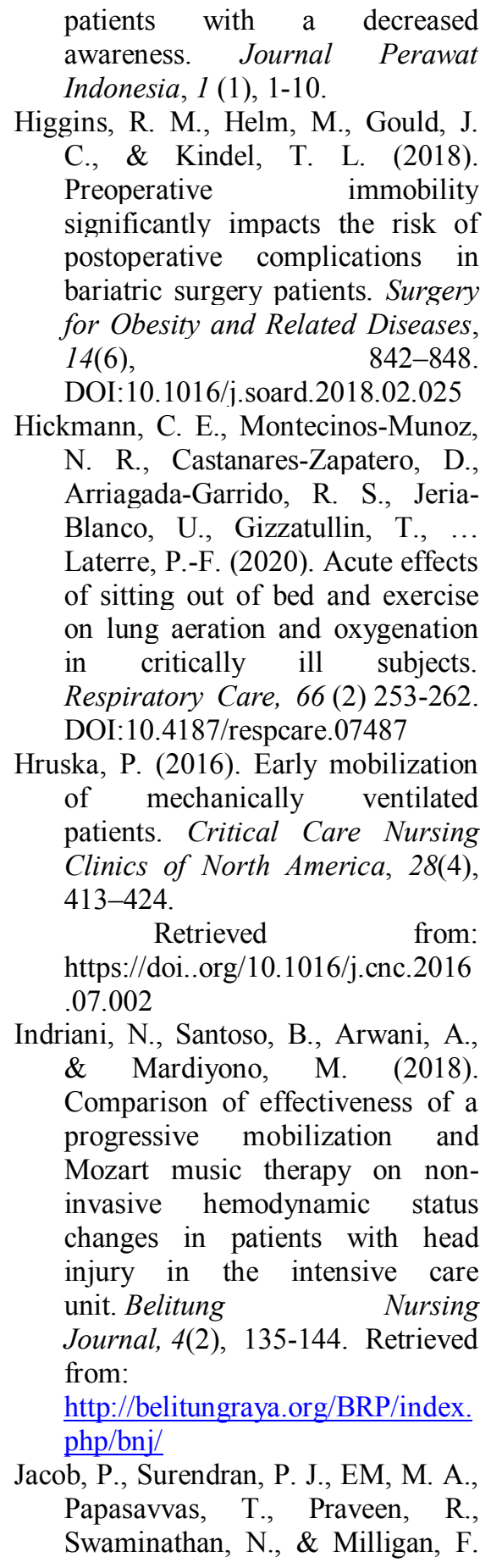 & 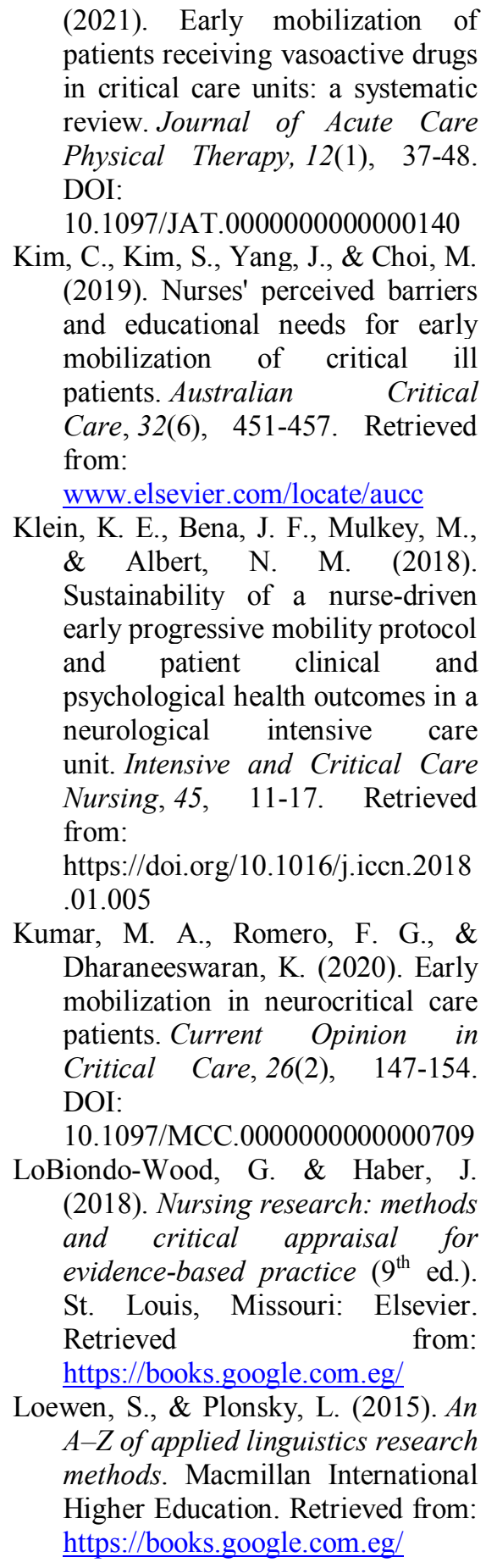 \\
\hline
\end{tabular}


Morton, P. G., \& Fontaine, D. K. (2018). Critical care nursing: a holistic approach. (1 $1^{\text {th }}$ ed.). Philadelphia: Lippincott Williams \& Wilikins.

Naito, Y., Kamiya, M., Morishima, N., \& Ishikawa, T. (2020). Association between out-of-bed mobilization and complications of immobility in acute phase of severe stroke: A retrospective observational study. Journal of Stroke and Cerebrovascular Diseases, 29(10), 105112.

Retrieved from: https://doi.org/10.1016/j.jstrokecer ebrovasdis.2020.105112

Ningtyas, N. W., Pujiastuti, R. S., \& Indriyawati, N. (2017). Effectiveness of progressive mobilization level I and II on hemodynamic status and decubitus ulcer risk in critically ill patients. Belitung Nursing Journal, 3(6), 662-669. Retrieved from:

http://belitungraya.org/BRP/index. $\mathrm{php} / \mathrm{bnj} /$

Parry, S. M., \& Puthucheary, Z. A. (2015). The impact of extended bed rest on the musculoskeletal system in the critical care environment. Extreme Physiology \& Medicine, 4(1), 1-8. DOI 10.1186/s13728-015-0036-7

Phelan, S., Lin, F., Mitchell, M., \& Chaboyer, W. (2018). Implementing early mobilization in the intensive care unit: An integrative review. International Journal of Nursing Studies, 77, 91-105.

DOI:10.1016/j.ijnurstu.2017.09.01 9

Pires-Neto, R. C., Kawaguchi, Y. M., Hirota, A. S., Fu, C., Tanaka, C.,
Caruso, P., ... \& Carvalho, C. R. R. (2013). Very early passive cycling exercise in mechanically ventilated critically ill patients: physiological and safety aspects-a case series. PLOS ONE, 8(9), e74182. DOI:10.1371/journal.pone.007418 $\underline{2}$

Rezaeikia, R., Najafi Doulatabad, S., Afrasiabifar, A., \& Zoladl, M. (2019). Effect of Passive Movements of Lower Extremity on Hemodynamic Parameters of the Patients under Ventilator. Journal of Clinical Care and Skills, 1(1), 37-42. Retrieved from: http://jccs.yums.ac.ir/article-1-29en.html

Santos, L. M., Novaes, A. P., Dantas, F. M., Ribeiro, L. C., Castro, C. M., \& França, E. E. (2019). Acute effect of passive cycloergometry on the cardiovascular system and respiratory mechanics of critically ill patients: a randomized controlled trial. Fisioterapia em Movimento, 32 . Retrieved from: https://doi.org/10.1590/19805918.032.ao32

Semsar-kazerooni, K., Dima, D., Valiquette, J., Berube-Dufour, J., \& Goldfarb, M. (2020). Early mobilization in people with acute cardiovascular disease. Canadian Journal of Cardiology. DOI:10.1016/j.cjca.2020.03.038

Taito, S., Shime, N., Ota, K., \& Yasuda, H. (2016). Early mobilization of mechanically ventilated patients in the intensive care unit. Journal of Intensive Care, 4(1), 50. DOI: 10.1186/s40560-016-0179-7

Tadyanemhandu, C., van Aswegen, H., \& Ntsiea, V. (2018). Early 
The Effect of Passive Range of Motion Exercises on etc...

mobilization practices of patients
in intensive care units in
Zimbabwean government
hospitals-a cross sectional
study. Southern African Journal of
Critical Care, 34(1), 16-21.
DOI:10.7196/SAJCC.2017.v34i1.
343
Thelandersson, A. Nellgård, B.
Ricksten, S. E., \& Cider, A. (2016). Effects of early bedside cycle exercise on intracranial pressure and systemic hemodynamics in critically ill patients in a neurointensive care unit. NeuroCritical Care, 25(3), 434-439. DOI $10.1007 / \mathrm{s} 12028-$ 016-0278-2

Trinity, J. D., \& Richardson, R. S. (2019). Physiological impact and clinical relevance of passive exercise/movement. Sports

Medicine, 1-17. DOI: 10.1007/s40279-019-01146-1

Vieira, J. V., Ferreira, R., Goes, M., Oliveira, H., Pacheco, R. G., \& Pereira, J. (2020). Early mobilization of the critically Ill patient: literature systematic review. Critical Care and Shock, 23, 54-64

Wang, T. H. (2020). Early mobilization on patients with mechanical ventilation in the ICU. In Physical Therapy Effectiveness.
IntechOpen. $\quad$ DOI: 10.5772/intechopen.89984

Wang, Y., Huang, Z., Duan, J., Xu, W., Mao, J., Yan, X., ... \& Lan, R. (2021). Effects of early mobilization (EM) in patients with noninvasive positive pressure ventilation (NIPPV) in Intensive Care Unit (ICU): a randomized controlled trial. Research Square, 12, 1-15. DOI: 10.21203/rs.3.rs$132343 / \mathrm{v} 1$

Younis, G., \& Ahmed, S. E. (2015). Effectiveness of passive range of motion exercise on hemodynamic parameters and behavioral pain intensity among adult mechanically ventilated patients. IOSR Journal of Nursing and Health Science, 4(6), 1-18. DOI: 10.9790/1959-04614759

Yilmaz Yelvar, G. D., Cirak, Y., Parlak Demir, Y., Dalkilinc, M., \& Bozkurt, B. (2016). Immediate effect of manual therapy on respiratory functions and inspiratory muscle strength in patients with COPD. International Journal of Chronic Obstructive Pulmonary Disease, 11, 1353. DOI:10.2147/copd.s107408

Zorowitz, R. D. (2016). ICU-Acquired Weakness. Chest, 150(4), 966971.

DOI:10.1016/j.chest.2016.06.006 